\title{
Chorea as the presentating feature of neurosyphilis
}

\author{
Serkan Ozben, Canan Erol, Feriha Ozer ${ }^{1}$, Raziye Tiras \\ Department of Neurology, and ${ }^{1}$ Movement Disorders Outpatient Clinic, Haseki Educational and Research Hospital, \\ Istanbul, Turkey
}

Address for correspondence:

Dr. F. Feriha Ozer

Atakoy 9, Kisim A14-B D:138,

Istanbul/TURKEY.

E-mail: ffozer@yahoo.com

DOI: $10.4103 / 0028-3886.53277$

\begin{abstract}
Syphilis is still a significant public health problem in developing countries. Although chorea is a very rare manifestation of neurosyphilis, it might be on occasions the initial symptom. This report presents a patients with neurosyphilis who had chorea as the initial presenting symptom.
\end{abstract}

Key words: Chorea, neurosyphilis, treponema pallidum

\section{Introduction}

The term "chorea" originates from the Greek word "choreia" meaning dance. Chorea is defined as irregular, unpredictable, brief, jerky hyperkinetic movements that flit randomly from one body part to another. ${ }^{[1]}$ Chorea may be a feature of a neurodegenerative disorder such as neuroacanthocytosis, dentarubropallidolusyian atrophy, or benign hereditary chorea and it can also be a rare manifestation of some very common diseases such as vascular diseases or hyperthyroidism. ${ }^{[2-4]}$ Other causes of chorea include drugs, central nervous system infections, and antiphospholipid syndrome and correcting the underlying disease should be the first step in the treatment of chorea. ${ }^{[2]}$

Syphilis is still a significant public health problem in developing countries. In the last few years, reports suggest increased incidence of syphilis globally; ${ }^{[5]}$ This may partly be due to the simultaneous increase in human immunodeficiency virus (HIV) infection. In the recent studies neuroshyphilis with atypical features is being more frequently reported. ${ }^{[6-8]}$ Awareness and testing for shphilis serology in an appropriate clinical setting is important. We report a patients with neurosyphils who had chorea as the initial presenting feature.

\section{Case Report}

A 70-year-old male presented to our outpatient clinic with movement disorder of 10-year duration. The movement disorder consisted of quick, unpredictable, jumping and jerking of the limbs. The symptoms first started in the right hand and right foot then spread to the left side over a period 3 years. These movements very much qualified to be categorized as chorea. Neurological and psychological examinations revealed no other abnormality. He had no prior history of exposure to neuroleptic drugs. Family history was negative for any movement disorder. He had history of hypertension of one year duration. He was prescribed haloperidol, initially $0.5 \mathrm{mg}$ twice a day and increased to $1 \mathrm{mg}$ three times a day, but there was no observable difference.

Routine biochemical and hematological tests were normal. Brain magnetic resonance imaging (MRI) revealed no abnormality. Fresh blood smear was negative for achantocytes. Serological tests for syphilis revealed: Venereal Disease Research Laboratory (VDRL) test $1 / 4$ reactive, positive rapid plasma reagin (RPR), and a positive Treponema-pallidum hemagglutinations-assay (TPHA). Cerebrospinal fluid (CSF) examination: Protein $-52 \mathrm{mg} / \mathrm{dL}$ (normal $15-45 \mathrm{mg} / \mathrm{dL}$ ), normal glucose, and no cells. CSF VDRL was positive. Fluorescent treponemal antibody absorption (FTA-ABS) test was positive in serum (1/640) and positive in CSF, HIV serology was negative.

He was treated with one dose of benzathine penicillin 2.4million IM and then with penicillin G 2.4 million IM per day for 14 days. His choreiform movements distinctly improved on the $12^{\text {th }}$ day of therapy. Repeat serological tests for syphilis in serum revealed $1 / 4$ positive VDRL, 1/4 positive RPR, positive TPHA, positive CSFVDRL, and positive FTA-ABS both in serum and CSF. He 
was subsequently treated with cephtriaxone $2 \mathrm{~g}$ per day IM for 10 days. After this therapy, only FTA-AB testing was done, it was positive in serum and negative in CSF. He was followed-up in the outpatient clinic at regular intervals. At six month follow-up he had minimal non-disabling chorea, but he was excited. He was not any medication for chorea.

\section{Discussion}

The exact anatomical substrate of chorea is not defined. Studies in patients with hemichorea suggest lesions involving basal ganglia, mainly the subthalamic nucleus as the substrate. ${ }^{[9-12]}$ Vascular lesions, ${ }^{[9-12]}$ vascular malformations, ${ }^{[13]}$ metastasis, ${ }^{[14]}$ infective granulomas, ${ }^{[15-17]}$ demyelinating lesions, ${ }^{[18]}$ and infectious diseases ${ }^{[19]}$ involving these anatomical structures may cause hemichorea. In our patient MRI did not reveal any structural lesion.

Syphilis is a chronic multisystem disease. An estimated $4-9 \%$ of patients with untreated syphilis develop symptomatic neurosyphilis. The three broad clinical categories of neurosyphilis are: Asymptomatic, meningovascular, and parenchymatous. Asymptomatic neurosyphilis is characterized by absence of clinical symptoms or signs and abnormal CSF including serology. Meningovascular syphilis results from inflammatory reaction of the perivascular spaces of the meninges, brain, and spinal cord. Tabes dorsalis (and general paralysis of the insane (GPI) are the parenchymatous forms of neurosyphilis. ${ }^{[20]}$

Only a few cases of neurosyphilis presenting with features of basal ganglia involvement have been documented in the recent literature and most of these patients had associated HIV infection. ${ }^{[21]}$ Our patient was negative for HIV. The choreiform movement responded to specific therapy for neurosyphilis. We had to give second line drug cephtriaxone as he did not show significant response with benzathin penicillin. Failure to penicillin therapy has been reported in patients with HIV and neuroshypilis. Recent reports suggest that neurosyphilis in patients with HIV may have risk of treatment failure. ${ }^{[22,23]}$

The "gold standard" for the diagnosis of neurosyphilis is not available. CSF leukocytosis and elevated protein are nonspecific and may support the diagnosis in a given clinical setting. A reactive serum treponemal test with a reactive CSF VDRL test is generally considered definitive for neurosyphilis. ${ }^{[24-27]}$

Although neurosyphilis is a very rare cause for chorea, when other diseases are excluded, it should be suspected and the serological test should be done. In the recent years with the availability of effective antibiotic therapy neurosyphilis with more atypical presentations are being described. Center for Disease Control and Prevention (CDC) recommends a CSF examination for all patients with syphilis infection who have neurological or ophthalmic symptoms and signs or who have active tertiary disease (aortitis, gumma, iritis) or have failed therapy. ${ }^{[28]}$

\section{References}

1. Jankovic J, Lang AE. Movement Disorders: Diagnosis and assessment In: Bradley WG, Daroff RB, Fenichel GM, Jankovic J, editors. Neurology in clinical practice: Principles of diagnosis and management. Vol. 1. $4^{\text {th }}$ ed. Philadelphia: Elsevier; 2006. p. 306-9.

2. Mark MH. Other choreatic disorders. In: Watts RL, Koller WC, editor. Movement Disorders: Neurologic Principles and Practice. $2^{\text {nd }}$ ed. New York: McGraw-Hill; 2004. p. 639-48.

3. Garcin B, Louissaint T, Hosseini H, Blanc R, Fénelon G. Reversible chorea in association with Graves' disease and moyamoya syndrome. Mov Disord 2008;23:620-2.

4. Quinn N, Schrag A. Huntington's disease and other choreas. J Neurol 1998;245:709-16.

5. Rompalo AM. Can syphilis be eradicated from the world? Curr Opin Infect Dis 2001;14: 41-4.

6. Rompalo AM, Lawlor J, Seaman P, Quinn TC, Zenilman JM, Hook EW $3^{\text {rd }}$. Modification of syphilis genital ulcer manifestations by coexistent HIV infection. Sex Transm Dis 2001;28:448-54.

7. Rompalo AM, Joesoef MR, O'Donnell JA, Augenbraun M, Brady W, Radolf JD, et al. Clinical manifestations of early syphilis by HIV status and gender: Results of the syphilis and HIV study. Sex Transm Dis 2001;28:158-65.

8. Alarcón F, Giménez-Roldán S. Systemic diseases that cause movement disorders. Parkinsonism Relat Disord 2005;11:1-18.

9. Altafullah I, Pascual-Leone A, Duvall K, Anderson DC, Taylor S. Putaminal hemorrhage accompanied by hemichorea-hemiballism. Stroke 1990;21:1093-4.

10. Fukui T, Hasegawa Y, Seriyama S, Takeuchi T, Sugita K, Tsukagoshi H. Hemiballism-hemichorea induced by subcortical ischemia. Can J Neurol Sci 1993;20:324-8.

11. Saris S. Chorea caused by caudate infarction. Arch Neurol 1983;40:590-1.

12. Vidaković A, Dragasević N, Kostić VS. Hemiballism: Report of 25 cases. J Neurol Neurosurg Psychiatry 1994;57:945-9.

13. Shintani S, Shiozawa Z, Tsunoda S, Shiigai T. Paroxysmal choreoathetosis precipitated by movement, sound and photic stimulation in a case of artero-venous malformation in the parietal lobe. Clin Neurol Neurosurg 1991;93:237-9.

14. Salama J, Gray F, Kemeny JL, Gherardi R, Delaporte P. Hemiballismus and metastasis to the Luys' body: An anatomo-clinical case. Rev Neurol (Paris) 1986;142:556-8.

15. Kalita J, Ranjan P, Misra UK, Das BK. Hemichorea: A rare presentation of tuberculoma. J Neurol Sci 2003;208:109-11.

16. Delaporte P, Salama J, Amarenco P. Subthalamic tuberculoma disclosed by hemiballism: Efficacy of antituberculous treatment. Ann Med Interne (Paris) 1983;134:728-31.

17. Ozer F, Meral H, Aydemir T, Ozturk O. Hemiballism-Hemichorea in presentation of cranial tuberculoma. Mov Disord 2006;21:1293-4.

18. Garretto NS, Bueri JA, Kremenchutzky M, Consalvo D, Segura M, Genovese O. Hemichorea associated with cerebral toxoplasmosis and AIDS. Arq Neuropsiquiatr 1995;53:118-22.

19. Namer IJ, Tan E, Akalin E, Selekler K, Zileli T. A case of hemiballismus during cryptococcal meningitis. Rev Neurol (Paris) 1990;146:153-4.

20. Luxon LM. Neurosyphilis. Int J Dermatol 1980;19:310-7.

21. Jones AL, Bouchier IA. A patient with neurosyphilis presenting as chorea. Scott Med J 1993;38:82-4.

22. Berry CD, Hooton TM, Collier AC, Lukehart SA. Neurological relapse after benzathine penicillin therapy for secondary syphilis in a patient with HIV infection. N Engl J Med 1987;316:1587-9.

23. Jorgensen J, Tikjob G, Weismann K. Neurosyphilis after treatment of latent syphilis with benzathine penicillin. Genitourin Med 1986;62:129-31. 
24. Centers for Disease Control and Prevention. Guidelines for treatment of sexually transmitted diseases. MMWR Morb Mortal Wkly Rep 2002;51:18-30.

25. Larsen SA, Johnson RE. Diagnostic test. In: Larsen S, Pope V, Johnson RE, Kennedy ED, editors. A manual of tests for syphilis. $9^{\text {th }} \mathrm{ed}$. Washington DC: American Public Health Association; 1998. p. 1-52.

26. Larsen SA, Hambie EA, Wobig GH, Kennedy EJ. Cerebrospinal fluid serologic test for syphilis: Treponemal and nontreponemal tests. In: Morisset R, Kurstak E, editors. Advances in sexually transmitted diseases. Utrecht: VNW Science Press; 1985. p. 157-62.
27. Johns DR, Tierney M, Felsenstein D. Alterations in the natural history of neurosyphilis by concurrent infection with the human immunodeficiency virus. N Engl J Med 1987;136:1569-72.

28. Verma A, Solbrig MV. Infections of the nervous system. In: Bradley WG, Daroff RB, Fenichel GM, Jankovic J, editors. Neurology in clinical practice: Principles of diagnosis and management. Vol. 2. $4^{\text {th }}$ ed Philadelphia: Elsevier; 2006. p. 1496-8.

Accepted on 24-02-2009

Source of Support: Nil, Conflict of Interest: None declared. 